\title{
Aborto, militância e subjetividade
}

\author{
Marcela Boni Evangelista ${ }^{1}$ (iD) 0000-0003-0413-6231
}

'Universidade de São Paulo, São Paulo, SP, Brasil. 05508-040 - edmfe@usp.br

\section{$-$}

Resumo: Neste artigo pretendemos discutir a temática do aborto a partir das narrativas de vida de duas militantes que se dedicam à luta pelos direitos das mulheres em diferentes movimentos sociais. Por meio dos aportes teóricos e metodológicos da história oral, foram realizadas entrevistas que posteriormente passaram por um processo de elaboração textual que resultou no material coletado, o qual foi a base para as reflexões apresentadas. A análise proposta busca abordar as relações entre a militância e a subjetividade e de que maneira viabilizam as discussões sobre o aborto para além dos números.

Palavras-chave: aborto; feminismo; história oral: militância; subjetividade.

\section{Abortion, Militancy and Subjectivity}

Abstract: The present article intends to discuss the abortion issue based on the two women activists's life narratives who are dedicated to the struggle for the women's rights in different social movements. Through the theoretical and methodological contributions of oral history, interviews were carried out, which later underwent a process of textual elaboration that resulted in the material collected, which was the basis for the reflections presented. The proposed analysis seeks to address the relationships between militancy and subjectivity and how discussions on abortion are feasible beyond numbers.

Keywords: Abortion; Feminism; Oral History: Militance; Subjectivity.

\section{O que os números não revelam}

Falar sobre aborto no Brasil envolve diferentes aspectos e possibilidades de abordagem. Das mais importantes estão, sem dúvidas, as que revelam a magnitude de um fenômeno social que, a despeito de suas raízes históricas, encontra pouco eco na Historiografia. Neste sentido, diversas áreas do saber são campos frutíferos para a realização de estudos que, a partir de métodos e aportes teóricos específicos, apresentam o aborto enquanto uma realidade social que demanda atenção e ações públicas.

As pesquisas mais recentes baseadas em análises quantitativas informam números alarmantes de casos de interrupção voluntária da gravidez no Brasil. De acordo com a Pesquisa Nacional do Aborto de 2016, no ano de 2015 cerca de meio milhão de mulheres interrompeu voluntariamente a gestação, sendo possível estimar que, aos 40 anos, quase uma em cada cinco mulheres brasileiras fez um aborto (Debora DINIZ; Marcelo MEDEIROS; Alberto MADEIRO, 2017).

Mesmo que nossas vidas sejam regidas por um Código Penal que criminaliza esta prática, ainda que não puna na mesma medida quem a ela recorre, é a base legal em que se apoiam inúmeras polêmicas sobre o aborto.

A primeira menção jurídica sobre o aborto remete ao Código Criminal do Império de 1830, quando era prevista punição aos facilitadores da prática, ficando a mulher menos visada enquanto culpada. Mudanças pouco expressivas se fizeram presentes na Constituição republicana, sendo que a lei que atualmente rege o aborto se refere ao Código Penal de 1940, que o criminaliza em todas as situações, exceto nos casos denominados legais. ${ }^{1}$ Nesta carta legal, somada à condição

' Os casos de aborto legal se restringem aos que resultam de estupro, risco de vida para a mãe e, mais recentemente, os de fetos anencéfalos. 
feminina marcada pelo patriarcado brasileiro, temos as mulheres como principais responsáveis pelo aborto.

A distância entre a lei e o cotidiano, por sua vez, nos remete à constatação de que falar de aborto não é falar de um crime, mas de uma questão moral. Em 2013 a Fundação Perseu Abramo, em parceria com o SESC (Gustavo VENTURI; Tatau GODINHO, 2013), publicou um estudo que divulga uma década de mudanças na opinião pública acerca de diversos assuntos pertinentes às mulheres e às questões de gênero. O aborto e a saúde reprodutiva foram abordados e os resultados da pesquisa chamam atenção por envolver tanto a opinião de mulheres quanto a de homens no que diz respeito a questões como o apoio ao aborto por parte dos companheiros e a punição que deve ou não ser aplicada às mulheres.

É possível verificar um mesmo caminho na lógica do senso comum no que se refere ao aborto e fica ainda mais claro por que é tão difícil falar sobre este tema, de modo que aqueles que se aventuram nesta seara são alvos de críticas ferrenhas, sobretudo, pelos setores mais conservadores de nossa sociedade.

E quem tem coragem de falar abertamente sobre o aborto? Historicamente, são os movimentos feministas os principais responsáveis pelo debate sobre o tema, assim como por ações que buscam promover esclarecimentos e políticas públicas comprometidas com avanços legais e institucionais.

Mas os movimentos sociais organizados não existem sem as pessoas que deles fazem parte. Quem são essas pessoas? Por que se dedicam a causas coletivas em momento marcado fortemente pelo individualismo? No caso do aborto, quais as implicações de defender uma questão envolta por polêmicas e preconceitos?

Procuraremos, neste artigo, discutir a questão do aborto à luz da experiência militante de duas mulheres que se dedicam a movimentos sociais organizados de cunho feminista e que apresentam em suas agendas a questão do aborto como essencial.

Amelinha Teles e Yury Orozco serão nossas interlocutoras e, por meio de suas histórias pessoais, permitirão adensar as discussões sobre o tema para além das análises quantitativas. A subjetividade de suas narrativas, associada ao caráter de representação que atestam, será o mote para revelar aspectos nem sempre considerados quando se relaciona aborto e militância.

Este artigo será estruturado em três tópicos: no primeiro apresentaremos os aspectos metodológicos adotados; em seguida apresentaremos um panorama geral sobre as relações entre feminismo e aborto em diálogo com as narrativas coletadas; por fim, propomos uma reflexão que busca observar o que as narrativas apresentam em comum, bem como o que as singulariza, abordando o potencial deste tipo de pesquisa que lida com as subjetividades e o papel destas personagens para possíveis avanços em relação às discussões sobre o aborto.

\section{História oral e subjetividade: a pesquisa além dos números}

O presente estudo se baseou nos aportes teóricos e metodológicos da história oral em consonância com a História do Tempo Presente (Lucilia DELGADO; Marieta FERREIRA, 2013) e teve como eixo a coleta de relatos cujo ponto em comum foi a experiência direta ou indireta de abortos induzidos. Ao final, foram realizadas 16 entrevistas de história de vida, sendo 13 com mulheres e três com homens. Diante da diversidade da natureza das trajetórias vividas, selecionamos para esta ocasião dois relatos que têm em comum o traço militante de suas protagonistas quando se trata do aborto, bem como seu comprometimento com grupos organizados.

Além disso, importa esclarecer que a pesquisa de modo geral teve como pressuposto a necessidade e a oferta de sigilo para as pessoas que concederam entrevistas. A exceção se deu justamente nos dois casos aqui relatados, os quais possuem não somente aspectos concernentes à subjetividade e às histórias particulares das interlocutoras, mas envolvem, de forma substancial, seu papel enquanto representantes de grupos organizados envolvidos com discussões de âmbito feminista. Desta forma, a decisão tomada em comum acordo com as colaboradoras se voltou para sua identificação, de modo que suas narrativas também projetam os discursos dos grupos aos quais pertencem e se dedicam. A ética da pesquisa se constrói, assim, na medida em que atende aos procedimentos metodológicos adotados e, sobretudo, às demandas de publicização dos movimentos sociais projetados pelas vozes das entrevistadas.

A realização das entrevistas em história oral guarda especificidades que permitem a coleta de histórias de vida que conferem sentido ao narrado. É importante ressaltar que o texto resultante desse encontro foi produzido pelo contato específico entre a entrevistadora e as entrevistadas. De acordo com Alessandro Portelli (2010), importante referência nas reflexões sobre a prática e a elaboração teórica em história oral, a interlocução estabelecida no momento da entrevista é inerente à qualidade do conteúdo registrado. São as características individuais em diálogo, com suas especificidades e similaridades, importantes traços da narrativa produzida.

Os sujeitos da entrevista, portanto, compartilham um espaço narrativo e um espaço físico - e é isso o que a torna possível. Mas o que a torna significativa é que existe também um espaço entre eles, ocupado e representado pelo gravador e pelo bloco de anotações. A entrevista, antes 
de mais nada, é um confronto com a diferença, com a alteridade (Alessandro PORTELLI, 2010, p. 213).

No que diz respeito ao momento atual em relação à discussão sobre o aborto, nos deparamos com diversos grupos organizados que postulam ideais feministas, ainda que partam de matrizes ideológicas diversas. Nesta ocasião, as narrativas coletadas fazem ecoar ideais de dois grupos reconhecidos por seu posicionamento militante: a União de Mulheres de São Paulo e o grupo Católicas pelo Direito de Decidir. ${ }^{2}$ Nossa proposta é ressaltar, além do aspecto institucional, as subjetividades de mulheres que, em sua trajetória, carregam tanto a responsabilidade coletiva à qual se identificam quanto suas próprias experiências. Buscamos, com isso, ir além dos números e mesmo do discurso oficial para adentrar a experiência pessoal que costura ativismo/militância e vida pessoal.

O que leva uma mulher a se dedicar à causa feminista? Quais os desdobramentos pessoais desta escolha? Qual o "peso" de defender a descriminalização ou legalização do aborto na sociedade brasileira atual?

Para responder a estas perguntas nos basearemos nas narrativas de duas mulheres que representam seus grupos e trajetórias pessoais. Tendo em vista a especificidade deste tipo de fonte, marcada pela subjetividade, nos apoiamos no potencial que a história oral oferece em relação aos estudos sobre a história das mulheres e das relações de gênero, de modo que permite registrar e valorizar suas memórias e narrativas. Assim, a memória coletiva se faz presente denotando mudanças nas concepções acerca da produção de conhecimentos, como ressalta as reflexões de Joan Pujadas (2000) acerca das possibilidades trazidas pelos diferentes documentos do campo da intimidade, como as autobiografias e, no caso desta pesquisa, os relatos de história de vida.

La construcción de la memoria, junto a las formas de afirmación de la identidad individual, así como las manifestaciones del "yo", reflejadas en las autobiografías y en otros tipos de documentos personales, nos muestran una pluralidad de voces y de sensibilidades en la interpretación de la realidad social que contrasta vivamente con un "canon" literario e ideológico que há sido hegemónico hasta hace bien poco (p. 129).

Diante de uma realidade histórica que revela profundas lacunas quando se trata de registros feitos por mulheres acerca de experiências que lhes dizem respeito, os estudos que envolvem suas memórias e narrativas se mostram promissores tanto na produção de documentos quanto na possibilidade de reflexão e análise a partir de pontos de vista alternativos.

As entrevistas gravadas em áudio foram transpostas para o texto escrito e submetidas ao processo de transcriação, procedimento inspirado em trabalhos de tradução literária e que demanda cuidados específicos que atentem para a performance narrativa.

Evocando pressupostos da tradução, a transcriação é a elaboração de um texto recriado em sua plenitude [...] A intenção é recriar a atmosfera, o contexto em que foi feita cada entrevista. [...] Esse procedimento de trabalho com as entrevistas orais se aproxima de uma recriação do universo visual e sonoro para o mundo da escrita, fundamentando-se nos estudos da literatura e da linguística... (José MEIHY; Suzana RIBEIRO, 2011, p. 110).

Procurou-se atender a pressupostos éticos que envolvem a valorização da intersubjetividade que permeia a entrevista e a produção do texto que dela se depreende. O texto reelaborado, contudo, necessita ser validado, ou seja, além da autorização formal, caracterizada pela assinatura de termos de cessão, a validação remete à identificação do colaborador com o texto final a ser utilizado para a análise. Somente após a verificação do material transcriado é que este se tornará público. Desta forma, aciona-se o potencial da colaboratividade.

A colaboração é sempre uma situação acordada, premeditada, discutida, jamais imposta ou improvisada e, neste sentido, a repartição dos poderes durante a fase de elaboração das entrevistas se dá no entendimento entre as partes, indo de um para outro em movimentos pendulares bem definidos: quem fala, diz o que quer; quem trabalha com a transposição do texto oral para o escrito atua de maneira a deliberar as melhores soluções; a autorização é dada em cima do que o entrevistado optar e, finalmente, o produto é integrado ao projeto segundo as propostas do diretor, mantidos os compromissos de uso moral da colaboração (MEIHY; Fabíola HOLANDA, 2010, p. 119).

Após a finalização da gravação, cada colaboradora foi acionada para conferir o texto a ser analisado. A possibilidade de revisão atribui ao procedimento colaborativo a oportunidade do narrador de confirmar se o que foi dito num primeiro momento é o que este deseja que seja "publicizado". Daí o cuidado necessário em trabalhos que lidam com a memória. É possível que o intervalo entre o momento da entrevista e da conferência aponte a necessidade de reparos e mesmo de novas lembranças, sempre atentas às condições subjetivas da trajetória de cada colaborador. Expor tal condição aos entrevistados garante sua participação no processo de

${ }^{2}$ Informações sobre os grupos em questão serão abordadas a partir dos relatos das entrevistadas ao longo do texto. 
elaboração documental e de construção da pesquisa, transformando-os em colaboradores e não meros informantes.

A opção metodológica, por fim, oferece as condições adequadas para abordar tema delicado como o aborto, especialmente por acionar aspectos íntimos dessa experiência. Permite, ainda, o aprofundamento de uma discussão que, a despeito da atenção que the tem sido dedicada, encontra dificuldades em abordar elementos que vão além dos números e valorizam as subjetividades e dilemas envolvidos.

\section{Feminismo e aborto: entre avanços e recuos}

O debate sobre o aborto no Brasil perpassa indiscutivelmente a trajetória do movimento feminista, cujo momento de retomada se encontra em meio ao ambiente ditatorial. Desta forma, as especificidades do feminismo brasileiro remetem a escolhas e posicionamentos que explicam a maneira como o mesmo abordou o tema do aborto. É também neste contexto que nossas colaboradoras se inserem enquanto pessoas que dedicariam suas trajetórias à luta pelas mulheres. Elas assim se apresentam:

Sou Maria Amélia de Almeida Teles, conhecida como Amelinha Teles. Nasci no dia 6 de outubro de 1944, em Contagem, Minas Gerais. Filha de comunista, criada no ateísmo, posso dizer que sou comunista de nascimento! Mas, não demorou muito para me tornar feminista! Afinal, comunista luta contra as injustiças, as desigualdades. Sendo mulher, para chegar ao feminismo não estava muito longe (Amelinha Teles).

Meu nome é Yuri Orozco. Nasci em 2 de janeiro de 1961, em Cartagena, Colômbia. Somos em seis irmãos, quatro homens e duas mulheres, que vivem na Colômbia. Há dois anos faleceram meus pais, os dois praticamente no mesmo dia... Os enterramos juntos na verdade. Ficamos sem referencial e está sendo uma experiência muito forte para toda a família... (Yury Orozco).

Antes mesmo de uma efetiva participação pública de questionamento às imposições sociais voltadas para as mulheres, Amelinha Teles já dava sinais de que não as aceitaria sem exigir explicações. Sua relação familiar, em especial com o pai, foi lembrada ao falar sobre a forma como iniciou seu processo de aproximação com temas que se tornariam centrais em sua trajetória militante. O mesmo se estendendo ao espaço da escola, onde destoava das outras crianças pelo interesse com que defendia temas como o aborto e o divórcio.

Sempre me interessei por assuntos como o aborto e o divórcio, ainda mais porque sou comunista e como diziam que isso era coisa de comunista, eu precisava saber do que se tratava. Cheguei a discutir esse assunto com o meu pai, que dizia: "Quando uma mulher precisar fazer um aborto, ela tem que fazer em condições de saúde adequadas. É isso que a gente tem que ver e não fazer qualquer besteira". Ele falava até mesmo para eu tomar cuidado! Eu tinha apenas 11 anos, estava entrando no ginásio, e já via que a luta era difícil! Lembro que defendi esta proposta em sala de aula na época. Apesar de acharem estranho uma menina de 11 anos defender a legalização do aborto e o divórcio, as pessoas pelo menos suportavam. Quer dizer, este era um debate suportável, embora realmente raro (Amelinha Teles).

A segunda metade do século XX foi marcada pelo conflito ideológico que opunha capitalismo e socialismo, tendo se desdobrado em diferentes correntes de pensamento e ação no mundo todo. Na América Latina, diversos movimentos sociais passaram a se organizar e, quando Yury Orozco era ainda uma adolescente, acabou por se integrar à Teologia da Libertação.

Minha adolescência foi marcada pela Teologia da Libertação, uma corrente ideológica que surgiu no campo do catolicismo e tinha um compromisso frente à situação de injustiça social, exclusão e pobreza, especialmente dos países do Terceiro Mundo. As igrejas se comprometeram a fazer uma leitura diferente da tradicional e criaram uma proposta pelos pobres, em que se fazia uma análise da realidade iluminada por teorias sociais, principalmente o marxismo, que analisava essa situação de pobreza e injustiça social como frutos de um modelo político-econômico injusto, que é o capitalista. Diante disso, as religióes não podem ser coniventes, então, a partir de uma teologia e uma ética devemos denunciar essas relações de injustiça e procurar saídas. A proposta da Teologia da Libertação era justamente sair desse modelo sócio-econômico (Yury Orozco).

No Brasil, as discussões em questão, que mobilizavam grupos engajados política e socialmente, seriam cerceadas pelo regime de exceção instaurado em 1964, mesmo ano em que Amelinha nasce para o feminismo:

Costumo dizer que tenho uma data de nascimento no feminismo: 19 de março de 1964! Alguns dias antes do golpe, os militares, junto com a igreja, os latifundiários e os empresários, mobilizaram mulheres para fazerem uma manifestação contra o presidente João Goulart. Falava-se em 250 mil mulheres! Claro que com esse número tinha ali mulheres pobres, negras, faveladas, ou seja, mulheres com as quais eu trabalhava, no sentido de conscientizá-las (Amelinha Teles). 
A década de 1970 é ponto de partida para o fortalecimento do feminismo de segunda onda, ainda amparado pela militância de esquerda de muitas de suas idealizadoras. O ano de 1975, por seu turno, representa momento imperativo no que tange ao apoio de instituições internacionais como a ONU, que naquele ano promoveu o "Ano Internacional da Mulher" (Joana Maria PEDRO, 2006; Cynthia SARTI, 2004).

A possibilidade de trazer à tona temas significativos para as mulheres naquele momento representou a necessidade de escolhas que se fariam importantes para angariar apoio de outros grupos, como de setores religiosos e partidários. Dentre elementos de relevância se encontram as dificuldades em tratar questões relativas à sexualidade, vistas como supérfluas perante a preponderância da luta contra a ditadura, o que era postulado especialmente pelos movimentos de esquerda. Amelinha, que se encaixava tanto no feminismo quanto no comunismo, começou a perceber em seu cotidiano esses dilemas.

Foi aí que percebi que tinha alguma coisa muito errada com a esquerda. Não sabia ainda dizer o que era, mas havia algo errado! Somente depois percebi que o problema era não ter um projeto político que garantisse um espaço protagonista para as mulheres. Estas seriam guiadas pela esquerda, mas não sujeitas da sua história. Infelizmente, quando percebi isto e me identifiquei definitivamente como feminista não havia muito mais tempo para debater. $\mathrm{Na}$ ditadura é assim, não tem liberdade para discutir, as pessoas são perseguidas o tempo todo! (Amelinha Teles).

O aborto, por sua vez, além de fazer parte destes temas "secundários", era ainda um problema-tabu diante do apoio da igreja católica que, para outros fins, era aliada privilegiada, dada sua força perante a formação de opiniões e a extensão de sua influência social e política (Mariza CORRÊA, 2001). Apesar disso, é importante considerar a pluralidade existente no âmbito da religião, permitindo vivências que não se circunscrevem a um modelo único, como nos apontou Yury a respeito de sua experiência pessoal:

Para mim, quando falam de religião, me vêm imediatamente minhas origens, de uma religião que me levasse a denunciar as injustiças sociais, a crença em um Deus comprometido com a busca de um mundo totalmente diferente. A experiência de falar de um Jesus Cristo histórico, que lutou no seu tempo contra as injustiças, denunciou tanto os ricos e políticos quanto a classe sacerdotal. Minha experiência critica toda concepção religiosa que leve as pessoas ao conformismo e a rezar simplesmente... (Yury Orozco).

A década de 1980 chega como momento de fortalecimento do movimento feminista, bem como suscetível a rupturas com setores apoiadores e mesmo em seu interior. A despeito disso, a temática do aborto ganha expressão e de alguma forma se solta das amarras antes atadas à igreja e aos partidos políticos (Leila BARSTED, 1992). Trata-se de uma fase marcada pela criação de entidades, organização de periódicos e realização de eventos e encontros de cunho feminista.

É neste contexto que criamos, em 1981, a União de Mulheres. Neste momento, surgem várias organizações feministas autônomas no Brasil e na América Latina. Era uma necessidade de ter espaço para a reflexão, para a ação, o estabelecimento de pautas e plataformas de luta. Antes disso, participei do Brasil Mulher e do Primeiro Congresso da Mulher Paulista, um encontro feminista onde foi discutida a questão da sexualidade, do direito de ter ou não filhos, a questão do aborto, do trabalho feminino, principalmente do assédio sexual, mas também da desigualdade salarial, enfim, essas coisas todas. A União de Mulheres sempre defendeu a legalização do aborto, assim como outras bandeiras feministas (Amelinha Teles).

O período marcado pela redemocratização foi repleto de iniciativas, sendo das mais essenciais as discussões acerca da nova Constituição, que seria promulgada em 1988. Amelinha Teles participou ativamente do processo da Constituinte, desde a promoção de discussões e elaboração de emendas populares, até o discurso que proferiu em defesa da legalização do aborto, como nos contou:

No processo da Constituinte, tivemos uma atuação fortíssima! No caso do aborto, uma parte das feministas achava que não devíamos falar claramente que queríamos o direito ao aborto, para evitar provocar os conservadores. Naquele momento, as alas conservadoras queriam que os primeiros artigos da Constituição, a cláusula pétrea, estabelecessem o direito à vida desde a concepção. Era hora de agir! Fomos para a rua fazer a emenda popular. E conseguimos! Nosso papel foi fundamental! Tanto que fui escolhida para fazer a defesa dessa emenda. Preparei o que ia defender junto com todas as mulheres, mas no dia da defesa fiquei extremamente sozinha. As mulheres ficaram no plenário e somente eu fui para dentro, como se fosse uma deputada. No momento da defesa, uma representante da igreja fez sua apresentação genericamente, com um discurso conservador e sem grandes efeitos. O discurso inovador ali era o meu mesmo! Defendia a legalização do aborto com todos os pingos nos "i"s e sem o apoio dos partidos políticos, que tinham medo de se comprometer. Foi muito duro, um momento de sofrimento solitário! (Amelinha Teles). 
Embora sem êxito na questão da constituinte, é possível inferir a intensificação das discussões sobre o tema do aborto e de pautas feministas na década de 1980, momento em que Yury deixa a Colômbia com destino ao Brasil. Aqui se dedicaria aos estudos de Teologia e, mesmo sem o saber, daria os primeiros passos em direção ao feminismo. Assim nos contou sobre suas primeiras experiências no país:

Fiquei sabendo desses cursos através de uma pessoa conhecida vinculada à instituição, que me convidou e aceitei de imediato! Nesse momento, apareceu uma figura muito importante no Brasil, Ivone Gebara, uma teóloga feminista. Naquele momento, o feminismo ainda estava muito distante para mim... Lembro que ela me perguntou: "Como é na Colômbia a questão das mulheres? Vocês têm movimentos próprios? Como é no trabalho que você faz?". Eu, ignorantemente, respondi: "Não! Para nós, o principal é a mudança do modelo econômico, político e social. Depois vem a questão das mulheres!". Era a concepção tanto da Teologia da Libertação como dos grupos de esquerda naquele momento... Totalmente marxista! Hoje acho ignorância pura ter falado isso, ainda mais para esta figura! (Yury Orozco).

Foi possível, mesmo com tais "avanços", verificar certa timidez no que diz respeito à relação entre o movimento feminista brasileiro e o debate sobre o aborto, o que se projeta em relação às dificuldades em avançar em conquistas relativas ao tema no país. Esta situação foi perceptível desde 1990, marcado por poucos avanços na discussão sobre a descriminalização do aborto (Lucila SCAVONE, 2008).

Importa ressaltar que isto não significa estagnação no ativismo feminista, mas a busca por alternativas de estabelecer diálogos com outros setores da sociedade, especialmente no âmbito político e jurídico, onde é possível verificar a ampliação do debate no que diz respeito à luta pela efetivação dos permissivos relativos ao aborto legal e à oferta de atendimento para os casos sob tal denominação. Além disso, merece destaque o avanço na busca pela ampliação de tais permissivos legais, especialmente no tocante às anomalias fetais, que obtiveram êxito na década seguinte.

É nesse ambiente que setores pouco atuantes na luta contra a criminalização do aborto, como a igreja, dão início a discussões em âmbito internacional e que, no Brasil, têm como representantes as Católicas pelo Direito de Decidir, grupo o qual Yury passará a integrar.

Terminando Teologia, me vinculei com as Católicas pelo Direito de Decidir num processo natural. Aqui comecei a me aprofundar muito mais nas argumentações que se usava e comecei a entender e conhecer todo o núcleo forte que era trabalhado pelo grupo, que era a questão do direito sexual e dos direitos reprodutivos. Houve também um vínculo maior com o movimento de mulheres e, acompanhando essa dinâmica, passei a conhecer as teorias feministas. Por isso posso dizer que estavam certos em ter medo de que mulheres e leigos entrassem e conhecessem, tomassem conhecimento do magistério, das argumentações e soubessem fazer reflexões teológicas. Com certeza sabiam que outros assuntos surgiriam e de maneira totalmente legítima, porque temos a chave para dizer não e por que não, para questionar, porque temos toda uma sustentação, um respaldo de ter estado junto com eles dentro dos estudos teológicos (Yury Orozco).

O recuo na radicalização do posicionamento dos movimentos feministas em relação à descriminalização e legalização do aborto, contudo, não pode ser ignorado e foi alvo de críticas por grupos que postulam a necessidade de avançar em tais aspectos.

Um dos pontos fracos das políticas feministas do aborto tem sido a impossibilidade material e simbólica de atingir um público maior [...], o que nos leva a concluir que essas negociações tiveram mais êxito em nível político do que social, pois não lograram alcançar e sensibilizar camadas mais amplas da população (SCAVONE, 2008, p. 679).

Neste sentido, cabe esclarecer a diferença entre descriminalização e legalização do aborto e o que simbolizam no universo da luta pelos direitos humanos das mulheres. A descriminalização se refere principalmente a não punibilidade das mulheres e profissionais que se utilizam de métodos de interrupção voluntária da gravidez, para isso sendo fundamental a retirada de seu estatuto de crime da legislação vigente. A impossibilidade de punição pelo aborto não reflete, no entanto, a ampliação de direitos, nem tampouco a oferta de serviços de atendimento para as mulheres que tenham esta opção. A legalização, por sua vez, remete ao estabelecimento do aborto enquanto um direito, o que direciona inevitavelmente medidas para que o mesmo seja executável em âmbito social e coletivo.

Com os esforços sendo voltados para os casos denominados de "aborto legal", por si só problemáticos no que tange à efetivação deste enquanto direito, o debate sobre a descriminalização e legalização enfraquece e, consequentemente, abre espaço para o fortalecimento de discursos conservadores e, em seu bojo, de retrocessos nos direitos já adquiridos. "A opção política pela descriminalização e pela efetivação dos casos previstos por lei, o percurso das políticas feministas para tratar do problema indicam não só o poder das forças conservadoras 
em jogo como a vocação política do feminismo brasileiro para a negociação" (SCAVONE, 2008, p. 676).

Podemos afirmar que o debate sobre o aborto encampado principalmente pelo movimento feminista vem sendo elaborado ao longo das últimas cinco décadas, contando com importantes conquistas, mas incontestáveis obstáculos, os quais têm se avolumado nos últimos anos paralelamente ao aumento de espaço de grupos conservadores. Amelinha Teles demonstra sua revolta em relação aos retrocessos.

No que diz respeito ao aborto, eu nem queria discutir. É uma questão de foro íntimo e não o Estado que deve legislar. Se uma pessoa está grávida e entende que não pode levar adiante a gravidez, faz-se um aborto com todas as condições para sua saúde física e mental. É um assunto de foro íntimo, mas deve ser tratado também do ponto de vista social e político. Ou seja, é preciso garantir que se fale sobre o assunto sem sofrer ameaças ou ser criminalizada.

Em meio a tal contexto foram e continuam sendo realizados estudos sobre o tema em diferentes campos de produção de conhecimentos, de modo que, diferente da década de 1970, hoje temos como lançar mão de instrumentos mais sólidos para lutar e enfrentar o problema. Estimativas são elaboradas frente à impossibilidade de mensurar oficialmente o fenômeno, dada a clandestinidade em que ocorre a maior parte dos procedimentos.

Dados de internação no Sistema Único de Saúde (SUS) mostram que a curetagem pós-aborto é o segundo procedimento obstétrico mais realizado nos hospitais públicos do país, superado apenas pelos partos, tendência que acompanha o que é observado no resto do mundo. As complicações do aborto inseguro representam a quinta causa de internação obstétrica no SUS. Isso mostra o elevado custo da criminalização do aborto para o sistema público de atenção à saúde no Brasil, já que tais complicações estão diretamente relacionadas às precárias condições em que o aborto é realizado no país, por ser considerado ilegal (Wilza VILLELA; Regina BARBOSA, 2011 , p. 57).

Tendo em vista as constatações observadas a partir de tais pesquisas, se intensificam as demandas por reflexões que problematizem a realidade vivenciada por inúmeras mulheres e a efetividade das políticas públicas disponíveis. Yury, em sua fala, elabora justificativas para a legalização do aborto.

Por que legalizar o aborto? Primeiro porque é um problema de saúde pública e segundo porque está plenamente confirmado que a proibição não ajuda a diminuir a incidência do aborto no mundo. Por isso, legalizar o aborto significa que o Estado deve criar condições de informação, de políticas públicas sobre planejamento familiar, de informações sobre saúde da mulher e um bom atendimento voltado para a saúde sexual e reprodutiva das mulheres para que possam vivenciar sua reprodução e sexualidade de uma maneira mais segura. Além disso, a legalização não significa que vai obrigar as mulheres a fazerem abortos de maneira arbitrária. Não consideramos que nenhuma mulher fará um aborto de maneira folclórica. Sabemos que as mulheres só recorrem ao aborto nas últimas consequências e esta decisão é sempre acompanhada de muito sofrimento e muita insegurança para as mulheres.

Estudos da área do Direito, da Sociologia e da Ciência Política trazem à tona os aspectos legais da questão, enquanto antropólogos se lançam ao campo para coletar material empírico que ilustra e problematiza o tema a partir de seus protagonistas (Fabíola ROHDEN, 2003; Alcilene CAVALCANTE; Dulce XAVIER, 2006; Rulian EMMERICK, 2008; Danda PRADO, 2007; Mônica MAIA, 2008; Flávia MOTTA, 2015; Luis MIGUEL; Flávia BIROLI, 2016). Profissionais da saúde oferecem elementos da realidade vivenciada nos serviços de atendimento, realçando o papel dos responsáveis pelo cuidado dispensado às mulheres que buscam apoio (BRASIL, 2009; Maurílio MATOS, 2010; VILLELA; BARBOSA, 2011). A Psicologia aprofunda a reflexão em seus aspectos subjetivos, ampliando o problema para além dos emergenciais. Historiadores e outros cientistas sociais oferecem bases explicativas para situação que remete a outras temporalidades, mas também ao tempo presente, buscando fontes e elaborando-as para que se possa compreender tema tão diverso e relevante socialmente (Giulia GALEOTTI, 2007; Silvia AREND; Gláucia ASSIS; Flávia MOTTA, 2012).

A despeito disso, as dificuldades permanecem e as lacunas se mantêm, sobretudo, no tocante aos aspectos subjetivos da experiência do aborto. É possível observar, por exemplo, que muito da atuação do movimento feminista em relação ao aborto tem como ponto de partida casos considerados exemplares. Na década de 1980, a gravidez provocada por estupro de uma adolescente teve o direito à interrupção da gestação recusado pelo corpo médico e tampouco foi resolvido pelos dispositivos legais disponíveis à época. A atuação do movimento de mulheres foi registrada amplamente, no entanto, pouco se diz sobre a vivência da protagonista ou de pessoas próximas a ela (BARSTED, 1992).

A imprensa tem sido veículo de grande relevância na denúncia de casos que se tornam paradigmáticos em função de desfechos trágicos. No entanto, pouco sabemos sobre essas pessoas, suas vidas ou o que delas restou, mesmo que isto somente fosse possível por meio da fala de outras 
pessoas com quem conviveram. Amelinha Teles fez questão de lembrar um desses casos, que ceifou a vida da jovem Jandira.

\begin{abstract}
Temos que ter um estado laico de verdade! A laicidade do Estado é fundamental para se compreender e tratar de forma mais aberta questões como as uniões homoafetivas, de sexualidade, a legalização do aborto, a legalização da maconha. É preciso ser mais coerente com a dignidade que defendemos enquanto sociedade democrática. Mas, ao contrário, o que acontece é que as mulheres continuam sendo expostas ao ridículo de perder a vida, ficar com o corpo desaparecido, como o caso da Jandira. E olha que falamos de 2014 e não do "meu tempo". Isto é um absurdo!
\end{abstract}

Para além da discussão sobre o indispensável papel do Estado, buscamos explanar a responsabilidade que tanto grupos organizados quanto indivíduos tomam para si quando $\circ$ problema não é somente pessoal, mas político!

\title{
Trajetórias de luta em movimento: assumindo lugares de fala e escuta
}

Apresentamos as histórias de duas mulheres que vivenciaram em diferentes espaços momentos históricos similares, até se encontrarem no mesmo contexto social e político que chega à atualidade. Brasil e Colômbia são os pontos de partida onde duas adolescentes se depararam com a luta por uma sociedade mais justa. Amelinha, assumindo o comunismo como traço de nascimento; e Yury se identificando desde muito cedo com a Teologia da Libertação e seu compromisso com o enfrentamento das desigualdades sociais. Ambas as narrativas emergem, portanto, de um posicionamento militante inicial, verificado ainda quando muito jovens e tendo vínculo indiscutível com a trajetória familiar de cada uma. A adolescência, para as duas protagonistas, se mostra o momento especial de descobertas e delineamento de posicionamentos, de onde se configura sua atuação, a despeito dos riscos e exposições a críticas.

A década de 1980, para Amelinha e Yury, tem significado especial de estabelecimento de espaços de atuação. A primeira se dedica à criação da União de Mulheres de São Paulo, enquanto a segunda decide pelo caminho da Teologia, tendo o Brasil como possibilidade de realização, passando na década seguinte a integrar o grupo Católicas pelo Direito de Decidir.

Embora com matrizes ideológicas distintas, ambas se veem diante do feminismo como causa a ser defendida e à qual se dedicarão nas próximas décadas. A militância, neste sentido, ganha cada vez mais espaço em suas trajetórias, ainda que se mantenham conectadas à família e à vida pessoal.

Ponto que apresenta a convergência das histórias de Amelinha e Yury é a ferrenha crítica ao capitalismo, seja pela identidade comunista da primeira ou pela significação religiosa que leva à luta contra as desigualdades sociais da segunda. Trata-se de um traço que remonta à atmosfera de questionamentos das décadas de 1960 e 1970, em que, a despeito dos regimes autoritários que se instauraram em diversos países latino-americanos, é indiscutível a atuação de pessoas e grupos contra tais investidas. Sendo assim, temos nas duas protagonistas que nos emprestam suas vozes exemplos claros de sujeitos que atuam contra um mesmo problema, que atinge tanto mulheres quanto homens, mas que, segundo suas experiências individuais, apontam, desde aquele momento, as mulheres como principais prejudicadas.

É nesse princípio que localizamos também o direito que as mulheres têm em optar por um aborto, baseado no princípio de autodeterminação das pessoas em decidir se querem ou não ter filhos, se querem ou não continuar com uma gravidez. Assim, nós, Católicas pelo Direito de Decidir, embora consideremos o aborto ponto importante, temos como primeiro princípio a autonomia e liberdade das pessoas. Consideramos que as mulheres têm capacidade ética e moral para decidir com liberdade se querem ou não continuar com a gravidez. Nós mulheres nos encontramos em situação de vulnerabilidade e violência em que muitas ficam grávidas não porque querem, mas por imposição dos maridos. Estamos num sistema de uma cultura machista e masculina (Yury Orozco).

Outro elemento que merece atenção e, inicialmente, distancia nossas interlocutoras, diz respeito à religião. Enquanto Amelinha se afirma ateia, Yury constrói sua militância respaldada pelo catolicismo, sendo fundamental relativizar seu olhar sobre a religião, cujo questionamento revela autonomia interpretativa sobre o que seja a crença e sua prática. Interessante pensar que o tema da religião, que tanto atravessa a discussão sobre aborto, possa ser ressignificado justamente quando do ponto de vista da teologia feminista.

O grupo surge, portanto, pelo momento em que a proposta coincide com um vínculo do feminismo internacional e regional com a expressão das mulheres teólogas, no encontro entre feminismo e Teologia Feminista, mesmo o surgimento desta. Nesse contexto, Católicas surge como uma proposta mais militante dentro do feminismo, nessa articulação entre feminismo e religião (Yury Orozco). 
Independente dos âmbitos de atuação de Amelinha e Yury, algo notável diz respeito às relações de gênero que estabelecem em suas jornadas. No caso de Amelinha, a questão se volta para a dinâmica dos partidos de esquerda, cuja prevalência de questões econômicas acaba por invalidar as demandas femininas e feministas. Em relação à Yury, temos ambiente também marcado pelas desigualdades entre mulheres e homens, que perpassa inclusive o acesso às discussões, monopolizadas por homens, e resvala no impedimento da atuação de mulheres e leigos que pretendam participar das reflexões teológicas.

E onde identificamos o tema do aborto?

O que nos levou a estas mulheres foi uma pesquisa sobre o tema do aborto. Entretanto, nossa abordagem, sendo de história oral de vida, colocava-nos a pretensão de conhecer suas trajetórias para além da conexão com o tema. E o que encontramos foi também surpreendente.

Amelinha compartilhou conosco uma experiência pessoal de aborto e maternidade ao narrar a situação por que passou enquanto vivia na clandestinidade.

Fiquei longo tempo na clandestinidade e foi nessa época que fiz um aborto. Tive a necessidade de fazer. Tinha dois filhos e era clandestina! Não havia razão para ter mais um filho, eu via que não tinha condições objetivas para criar uma criança. Mal conseguia criar os dois que tinha, imagine mais um! Um companheiro médico fez o aborto em mim em uma casa, com todas as condições e me deu toda a atenção necessária.

Fiz um aborto seguro embora vivesse na clandestinidade! O paradoxo é que hoje vejo mulheres precisando fazer um aborto e tendo que fazer de forma insegura e clandestina, mesmo sabendo que vivemos uma democracia! Ainda assim, o aborto continua clandestino! Algo que deveria ser entendido como um direito humano fundamental é realizado na clandestinidade! No meu caso, o aborto foi clandestino porque eu era clandestina! A vida nos havia empurrado para isto, a ditadura não permitia que fosse diferente. Hoje vejo mulheres enfrentando a mesma ditadura, mas em outro sentido, precisando fazer clandestinamente o aborto e sofrendo gravíssimas consequências! (Amelinha Teles).

Yury, mesmo sem ter vivenciado um aborto, dedica sua vida às mulheres que precisam recorrer a este procedimento.

Quando você se situa por uma ética que coloca como centro os seres humanos, não tem como negar a possibilidade de que uma pessoa seja livre para, em consciência, decidir alguma coisa sobre sua vida. O aborto se encaixa nisso porque se você é uma pessoa autônoma, livre, com capacidade de decidir, por que vou negar essa possibilidade a você? Que exerça sua liberdade, sua autonomia, seu poder de decisão frente a qualquer circunstância da vida! Se eu luto pela justiça, por que tenho que ser injusta contra você? Mesmo que não pense da mesma forma, você está no centro e suas necessidades, escolhas de vida devem ser respeitadas. 0 desafio maior é oferecer possibilidades para que as pessoas tenham informação e possam escolher da melhor maneira possível, façam uma boa escolha (Yury Orozco).

Em seus relatos fica explícita a preponderância do coletivo sobre suas vidas particulares, algo característico de quem se dedica à militância. Contudo, suas narrativas revelam subliminarmente as implicações desta escolha.

É a luta pelas mulheres que movimenta suas trajetórias. E abdicar de uma vivência prosaica para a maioria das mulheres representa colocar em segundo plano questões íntimas como a maternidade, além da coragem de se expor a estigmas socialmente enraizados. De maneira muito esclarecida, suas escolhas são significadas de forma decidida, apesar das consequências. É a militância que confere tônus a suas vidas.

Estou nesta luta há muito tempo! São praticamente 70 anos! Passei a vida inteira lutando e acompanhando a vida do povo, nunca me afastei até por uma questão de ideologia. Por isso, posso dizer com convicção que, na questão do aborto, estamos muito atrasados! Podemos dizer mesmo que retrocedemos! Não se pode tocar na palavra "aborto". E olha que estamos com três mulheres candidatas à presidência na campanha eleitoral deste ano! Ninguém fala nada! O assunto está literalmente silenciado, interditado, censurado. Que democracia é esta? Nesta democracia, não cabem as mulheres... (Amelinha Teles).

Mas por trás deste trabalho incessante pelo coletivo, vivem duas mulheres de carne, osso e sentimentos. Em seus relatos, ainda que o discurso militante seja preponderante, conseguimos observar dilemas e enfrentamentos do cotidiano, algo que humaniza estas vozes que se dedicam a falar por e sobre outrem.

Suas realizações postulam preocupações que envolvem centenas de milhares de mulheres, cuja magnitude numérica não permite revelar a subjetividade de suas experiências. Falamos, portanto, de duas mulheres cujas vidas se dedicam a fazer ecoar tantas outras vidas. E o que as move e lhes dá base jamais seria possível entrever entre estatísticas. Trata-se de buscar a subjetividade e humanizar mesmo os discursos mais dedicados à causa coletiva.

Nunca fiz um aborto, mas penso que se me deparasse com uma gravidez indesejada não pensaria duas vezes e faria também. Em minha vida pessoal, o trabalho é algo central e 
aperta muito! Me vejo muitas vezes limitada e isso é um problema [com] que nós, mulheres, lidamos. O trabalho aqui em Católicas não é um exercício administrativo, que você está no escritório, ou de uma professora que dá aulas de segunda a sexta e quando fecha a escola vai embora e acabou. Aqui levamos o trabalho para a cama, para as férias. Mesmo dentro do feminismo temos essa como uma preocupação, pois está na proposta de como você cuida de si e muitas vezes nos descuidamos tamanha é a entrega! (Yury Orozco).

Falar sobre o aborto é também falar sobre as mulheres que, tendo ou não passado por esta experiência, dedicam suas vidas para que todas elas possam escolher e decidir sobre seus corpos e destinos.

Diferente de muitas mulheres, para elas, o aborto não é motivo de silêncio, mas um "lugar de fala" (Djamila RIBEIRO, 2017; Marcia TIBURI, 2018). Sua militância e dedicação de uma vida inteira fazem ecoar vozes de milhares de mulheres que permanecem silenciosas e silenciadas pela criminalização e clandestinidade.

Sua coragem não reside apenas em falar e reverberar uma demanda coletiva, mas abdicar de suas próprias vidas pessoais em favor de uma causa social que contempla todas as mulheres. Sejam as que passaram por um aborto, sejam as que um dia - sem sequer imaginar - possam precisar recorrer a esta escolha.

Suas histórias pessoais, atravessadas por um discurso "oficial" feminista e ativista, revelam fragilidades, escolhas e momentos de solidão. Aspectos que nem os números, nem tampouco sua exposição pública permite entrever.

\begin{abstract}
Minha vida é totalmente ligada a essas lutas. Mas, tem momentos que paro um pouco e gosto de andar... Sozinha, acompanhada, com os meus cachorros, não importa, eu gosto mesmo é de andar! Mas, também gosto de apreciar as artes: cinema, teatro, artes plásticas, música, de preferência MPB, mas também latino-americana, os cubanos, tangos argentinos... Tango acho algo assim muito chocante, impactante! Gosto disso!

Algo que me choca e me chama atenção é um sonho que tenho de vez em quando... Sonho que estou voando e até parece que vou cair da cama... E quando estou acordada, nossa, tenho muitos sonhos! Sonho com um mundo mais justo e melhor! Um sonho muito simples que tenho é que as mulheres que sofrem violência e, depois da Lei Maria da Penha, podem denunciar seus agressores, não fossem mais mortas. Mas, infelizmente, não é isto que está acontecendo... As mulheres continuam morrendo. A cada noventa minutos uma mulher é assassinada no Brasil (Amelinha Teles).
\end{abstract}

Amelinha e Yury fazem parte de uma minoria (desde o fato de serem mulheres, até seus âmbitos de atuação original - a lgreja Católica e os partidos de esquerda). Na medida em que, no entanto, assumem a militância feminista, passam a um lugar de fala e escuta, ao atentarem para demandas de uma "minoria" ainda "maior", que é a das mulheres que ainda não se apropriaram de um "lugar de fala". Passam a um lugar de escuta que visa a representar um grupo e, por ele, assumem um lugar de fala.

A projeção de estudos e reflexões sobre o que seja "lugar de fala" em todo momento ressalta que não se trata de uma descoberta ou algo novo, mas tão somente de uma necessidade que urge ser atendida. A fala sempre houve, assim como os diversos lugares de onde provém. Provavelmente falamos muito mais da ausência de uma escuta para estas falas.

Já faz algum tempo que campos do saber se ocupam em ouvir, seja um suposto "outro" ou aquele com quem se identifica. A preocupação em ouvir revela, portanto, a necessidade de se pensar um "lugar de escuta".

É o desejo político que surge no lugar de fala. O lugar de fala pede, no entanto, um lugar de escuta. O lugar de fala expressa um desejo de espaço e tempo contra uma ordem que favorece uns em detrimento de outros. A escuta é um elemento prático no processo político que precisa ser experimentado com urgência, sobretudo pelos sujeitos que detêm o privilégio da fala (TIBURI, 2018, p. 56).

A história oral é forma de produção de conhecimentos que guarda raízes no exercício da escuta e sua reverberação. Assume-se, desta forma, de início, a produção de um lugar de escuta que pretende acenar lugares de fala preexistentes. $E$ isto se dá por meio de um processo de trabalho intenso de valorização de identidades e, ao mesmo tempo, singularidades.

Amelinha e Yury personificam, neste sentido, lugares de escuta e de fala e contribuem, a partir de suas singularidades e coragem em falar sobre si, um espaço em que a militância se une à subjetividade e projeta a necessidade de desestigmatizar o ser mulher, bem como as demandas que encampam, em que o aborto é mote central para a conquista de autonomia e liberdade feminina.

\title{
Referências
}

AREND, Silvia Maria Fávero; ASSIS, Gláucia de Oliveira; MOTTA, Flávia de Mattos (Orgs.). Aborto e contracepção. Histórias que ninguém conta. Florianópolis: Insular, 2012. 
BARSTED, Leila de Andrade Linhares. "Legalização e descriminalização: 10 anos de luta feminista". Revista Estudos Feministas, v. 0, n. 0, 1992.

BRASIL. 20 Anos de pesquisa sobre aborto no Brasil. Brasília: Ministério da Saúde, 2009.

CAVALCANTE, Alcilene; XAVIER, Dulce (Orgs.). Em defesa da vida: aborto e direitos humanos. São Paulo: Católicas pelo Direito de Decidir, 2006.

CORRÊA, Mariza. "Do feminismo aos estudos de gênero: um exemplo pessoal". Cadernos Pagu, $\mathrm{n}$. 16, p. 13-30, 2001.

DELGADO, Lucilia de Almeida Neves; FERREIRA, Marieta de Moraes. "História do tempo presente e ensino de História". História Hoje. Revista de História e Ensino, v. 2, n. 4, 2013.

DINIZ, Debora; MEDEIROS, Marcelo; MADEIRO, Alberto. "Pesquisa Nacional de Aborto 2016". Ciência e Saúde Coletiva, v. 22, n. 2, p. 653-660, 2017.

EMMERICK, Rulian. Aborto. (Des)criminalização, Direitos Humanos, Democracia. Rio de Janeiro: Lumen Juris, 2008.

GALEOTTI, Giulia. História do Aborto. Coimbra: Edições 70, 2007.

MAIA, Mônica Bara. Direito de decidir: múltiplos olhares sobre o aborto. Belo Horizonte: Autêntica, 2008.

MATOS, Maurílio Castro de. A criminalização do aborto em questão. São Paulo: Almedina, 2010.

MEIHY, José Carlos Sebe Bom; HOLANDA, Fabíola. História oral: como fazer, como pensar. São Paulo: Contexto, 2010.

MEIHY, José Carlos Sebe Bom; RIBEIRO, Suzana Lopes Salgado. Guia prático de história oral. São Paulo: Contexto, 2011.

MIGUEL, Luis Felipe; BIROLI, Flávia (Orgs.). Aborto e democracia. São Paulo: Alameda, 2016.

MOTTA, Flávia de Mattos. Sonoro silêncio: história e etnografia do aborto. Ponta Grossa: Toda Palavra, 2015.

PEDRO, Joana Maria. "Narrativas fundadoras do feminismo: poderes e conflitos (1970-1978)". Revista Brasileira de História, v. 26, n. 52, p. 249-272, 2006.

PORTELLI, Alessandro. Ensaios de história oral. São Paulo: Letra e Voz, 2010.

PUJADAS, Joan J. "El método biográfico y los géneros de la memoria". Revista de Antropología Social, p. 127-158, 2000.

PRADO, Danda. O que é aborto. São Paulo: Brasiliense, 2007.

RIBEIRO, Djamila. O que é lugar de fala? Belo Horizonte: Letramento; Justificando, 2017.

ROHDEN, Fabíola. A arte de enganar a natureza: contracepção, aborto e infanticídio no início do século XX. Rio de Janeiro: EDFIOCRUZ, 2003.

SARTI, Cynthia Andersen. "O feminismo brasileiro desde os anos 1970: revisitando uma trajetória". Revista Estudos Feministas, v. 12, n. 2, 2004.

SCAVONE, Lucila. "Políticas feministas do aborto". Revista Estudos Feministas, v. 16, n. 2, p. 675-680, 2008.

TIBURI, Marcia. Feminismo em comum: para todas, todes e todos. Rio de Janeiro: Rosa dos Tempos, 2018.

VENTURI, Gustavo; GODINHO, Tatau (Orgs.). Mulheres Brasileiras e Gênero nos Espaços Público e Privado: uma década de mudanças na opinião pública. São Paulo: Fundação Perseu Abramo; SESC, 2013.

VILLELA, Wilza Vieira; BARBOSA, Regina Maria. Aborto, saúde e cidadania. São Paulo: EDUNESP, 2011. 
Marcela Boni Evangelista (marcela.boni@gmail.com) possui Graduação (2005), Mestrado (2011) e Doutorado (2017) em História pela USP. Atualmente é coordenadora do Núcleo de Estudos de História Oral (NEHO-USP) e pesquisadora do Grupo de Pesquisa em Gênero e História da USP (GRUPEG-HIST). Tem como temas de interesse em pesquisa: história oral, história das mulheres, gênero, violência, direitos humanos e metodologia do ensino de História. É também professora da Faculdade de Educação da USP (FE-USP).

\section{COMO CITAR ESSE ARTIGO DE ACORDO COM AS NORMAS DA REVISTA}

EVANGELISTA, Marcela Boni. "Aborto, militância e subjetividade". Revista Estudos Feministas, Florianópolis, v. 28, n. 2, e $58758,2020$.

\section{CONTRIBUIÇÃO DE AUTORIA}

Não se aplica.

\section{FINANCIAMENTO}

FAPESP - Fundação de Amparo à Pesquisa do Estado de São Paulo.

\section{CONSENTIMENTO DE USO DE IMAGEM}

Não se aplica.

APROVAÇÃO DE COMITÊ DE ÉTICA EM PESQUISA

Não se aplica.

\section{CONFLITO DE INTERESSES}

Não se aplica.

LICENÇA DE USO

Este artigo está licenciado sob a Licença Creative Commons CC-BY International. Com essa licença você pode compartilhar, adaptar, criar para qualquer fim, desde que atribua a autoria da obra.

\section{HISTÓRICO}

Recebido em 21/08/2018

Reapresentado em 24/11/2019

Aprovado em 24/01/2020 